\section{Consumers' valuation of two packaging aspects for fresh lamb meat: Vacuum and information labels}

${ }^{1}$ Departamento de Ciencias Agrarias y del Medio Natural, Universidad de Zaragoza, C/ Miguel Servet 177, Zaragoza 50013, Spain

${ }^{2}$ Unidad de Economía Agroalimentaria y de los Recursos Naturales, Centro de Investigación y Tecnología Agroalimentaria de Aragón (CITA), Avda Montañana 930, Zaragoza 50059, Spain

${ }^{3}$ Instituto Agroalimentario de Aragón-IA2 (CITA-Universidad de Zaragoza), Zaragoza, Spain

Correspondence

Azucena Gracia, Unidad de Economía Agroalimentaria y de los Recursos Naturales, Centro de Investigación y Tecnología Agroalimentaria de Aragón (CITA), Avda Montañana 930, Zaragoza 50059, Spain. Email: agracia@cita-aragon.es

\section{1 | INTRODUCTION}

The main functions of packaging are containment, protection and preservation, convenience, and communication. ${ }^{1}$ Moreover, the role of packaging is also to attract consumers' attention to influence consumers' food choices. ${ }^{2}$ For fresh food produce sold in the supermarket shelves, the primary functions of containment, protection, and preservation are of vital importance for retailers to ensure that the product is safely commercialized to the consumer. These functions are also more relevant for fresh food products with low rate of turnover in the supermarket shelves. One example of fresh food with low rate of turnover is the fresh lamb meat sold in the supermarkets for 2 reasons. First, the consumption of lamb meat is continuously decreasing. Globally, lamb and goat-meat consumption accounted for $1.9 \mathrm{~kg} /$ capita, much lesser than the consumption of other alternative meats (15.8 for pork, 13.6 for poultry, and 9.6 for beef). ${ }^{3}$ Moreover, the consumption of lamb meat has been declining in the last few years, and it is a marginal meat in the consumer basket. ${ }^{4}$ In the case of Spain, the consumption of lamb meat at home has declined around $40 \%$ in the last 10 years ${ }^{5,6}$ from $2.7 \mathrm{~kg} /$ capita/ year in 2006 to $1.7 \mathrm{~kg} / \mathrm{capita} /$ year in 2015 . Second, the frequency of consumption of this meat is lower than other meat type of meats. ${ }^{7}$ This decreasing trend of consumption and the lower frequency of consumption of the lamb meat induce a low rate of product turnover in the supermarket shelves.

In this context, Spanish retailers have difficulties to sell the fresh lamb meat by the expiration dates, and they should throw away lamb-meat packages with the corresponding economic losses. To solve this problem, 1 possible alternative is using a vacuum packaging ${ }^{\dagger}$ that is been using now only for imported frozen lamb meat to extend the shelf life of the fresh lamb meat from 5 to 8 days to 20 to 25 days for fresh cut or uncut meat, respectively. Although vacuum packaging has been used in Spain for several food products (mainly for cured meat with few examples for fresh meat for special cuts such as certified fresh beef, duck breast, and pork sirloin), it has been never used to sell fresh lamb meat in supermarkets. In addition, vacuum packaging has other advantages for retailers and consumers because it provides them convenience ${ }^{13}$ and might increase the perception that the meat 
is safe and healthy. Also, in the case of fresh lamb meat, mandatory information on different aspects has increased as a consequence of food crises in Europe. This information must be clearly presented in the package. Then, the role of communication of the packaging becomes more important. Retailers can use different types of labels to provide the mandatory information on the product, and these labels should be designed in the way that attracts more consumers' attention to the product. In this context, Spanish retailers are making efforts to improve the packaging of the lamb fresh meat, and they start offering fresh lamb meat in vacuum packaging and designing different labels to communicate the mandatory information to get consumers' attention. However, it is difficult to anticipate the level of consumer acceptance of this packaging for this particular fresh meat and the liking or preferences for the different labels. This is the objective of the paper, to investigate the acceptance of vacuum packaging and to assess consumers' valuation for different labels.

Several studies have analysed consumers' acceptance of different packages for fresh beef meat. Schmitz et $\mathrm{al}^{14}$ studied consumers' willingness to pay (WTP) for vacuum skin-packaged beef steaks in the United States. They found that positive information about vacuum packaging was a necessary condition to successfully market vacuum-sealed beef steaks. Chen et al ${ }^{15}$ examined consumer perceptions and estimated the consumers' WTP for vacuum packaging of fresh beef in Canada. The findings suggested that information about the positive and potential negative properties of vacuum packaging plays an important role in WTPs for vacuum-packaged beef steaks. Grebitus et $\mathrm{al}^{16}$ studied US and German consumer preferences for ground beef packaged under a modified atmosphere packaging. They found that providing information on the use of carbon monoxide in the packaging decreased US consumers' WTP and increased German consumers' WTP.

All previous studies were conducted for fresh meat in North America except for Grebitus et al $^{16}$ that compares US and German consumers' preferences. They mainly studied the influence of information about the 2 new packaging technologies in consumers' WTP for beef (vacuum and modified atmosphere). However, our study will also examine consumers' preferences for lamb meat in 1 European country. Moreover, the specific objective of our paper differs from the previous ones because this paper measures the consumers' relative importance of the vacuum packaging in relation to other important lamb-meat characteristics (type of cut, price, regional quality certification, and type of label). As far as we know, this is the first time that consumers' preferences for vacuum packaging have been studied for fresh lamb meat. In addition, it is the first time that a study investigating preferences for the vacuum packaging has been conducted in Europe, except for Grebitus et $\mathrm{al}^{16}$ study, which compared US and German consumers' preferences but for a modified atmosphere package.

Data were gathered using a survey administrated to lamb-meat consumers in a northeast Spanish region (Aragón). This region was selected because this is one of the regions with the highest production and consumption of lamb meat in Spain. ${ }^{\ddagger}$ To reach our objective, a choice experiment $(C E)^{\S}$ was used with different levels of several lamb-meat characteristics (price, type of cut, regional quality certification, type of packaging, and type of label).

\section{2 | MATERIALS AND METHODS}

To achieve the objective, a CE was used for its ability to value multiple attributes simultaneously, its consistency with the random utility theory, and the similarity of the choice task asked of participants to their real purchase decisions. ${ }^{18}$ In the choice modelling approach, consumers have to choose several times between alternative products with several attributes having different levels. This task is similar to the consumer shopping behaviour, and this familiarity is the main advantage of the CE method. Therefore, the CE is the most commonly used valuation technique to value food products with several attributes. After the CE, participants had to respond to a questionnaire asking questions about their meat consumption frequency, the degree of knowledge, use and satisfaction with the vacuum packaging, and respondents' socio-economic and demographic characteristics.

\section{1 | CE and consumer preferences}

The CE method is based on the Lancaster theory, which assumes that consumers follow a utility-maximising behaviour. Then, for a number of relevant attributes and levels of these attributes, the individual's utility obtained from alternative product $j$ is Unj, $j=1, \ldots, \mathrm{J}$. The individual chooses the alternative that provides the greatest utility. Then, the $n$th individual would choose the alternative $j$ if and only if Unj > Unk $\forall j \neq k$.

The consumer utility function is known to the individual but not to the researcher. The researcher observes some attributes of the products and some characteristics of the consumer, but some components of the utility are unobservable and treated as stochastic according to the random utility model. ${ }^{19}$ Then, the utility is considered a random variable where the utility from the $n$th individual facing a choice among $j$ alternatives within choice set $J$ in each of $t$ choice sets can be represented as

$$
U_{n j t}=\beta_{n}^{\prime} X_{n j}+\varepsilon_{n j t},
$$

where

$n \quad=1, \ldots, N$ is the number of respondents.

$j \quad=$ number of alternatives within choice set $J$.

$t \quad=$ number of choice sets.

$X_{n j}=$ M-dimensional column vector of observed variables related to alternative $j$ and respondents $n$.

$\beta_{n} \quad=$ M-dimensional row vector of individual parameters.

$\varepsilon_{\text {njt }} \quad=$ extreme value error term $\left(0, \sigma^{2}\right)$, iid over alternatives, and independent of $\beta$ and $x$.

Depending on the different assumptions of the density of this random term $f\left(\varepsilon_{n i t}\right)$, different specification of the choice model can be specified. The selection of this density function is based on the assumptions of consumers' preferences. Traditionally, it has been assumed that consumers were homogeneous in terms of preferences and a multinomial logit (MNL) model was used. ${ }^{19}$ However, it is commonly accepted that this assumption of homogenous consumers' preferences should be relaxed and allow preferences to be heterogeneous. In the latter case, a generalisation of the MNL model should be 
specified. A random parameters logit (RPL) model was used, considering a panel structure as each individual made different choices. ${ }^{20}$ Moreover, correlations across utilities and across taste parameters were assumed and an error-component random-parameter logit (ECRPL) with correlated errors was specified.

Correlation across utilities can be generated because the nonbuy option is really experienced by the consumer while the experimental alternatives are designed and vary across choice tasks. Therefore, the utilities of the designed options might be more correlated between them and have higher variance than do the utilities of the nonbuy alternative. In other words, the experimental designed alternatives could share an extra error component that is not present in the utility ance of experimentally designed alternatives, an additional error component must be included in the specification of the model. This new model is called ECRPL and has been used in several empirical applications, being very successful because it is parsimonious (it only requires 1 extra parameter) and improved the model fit. ${ }^{22}$ In addition, correlation across taste parameters can be expected if some attributes are interdependent. In this case, the correlation structure of $\beta_{n}$ should follow a multivariate normal distribution (normal with vector mean $\mu$ and variance-covariance matrix $\Omega$ ). If at least some of the estimates for elements of the Cholesky matrix $C$ (where $C^{\prime} C=\Omega$ ) are statistically significant, this means that dependence across tastes exists. ${ }^{23}$

\section{2 | CE design}

The first step in the design of a CE is to choose the product to be analysed and their attributes and levels. Apart from the type of packaging and type of label attributes that are the objectives of the paper, this selection was done using lamb-meat expert opinions. Experts suggested using a half-kilo package of fresh lamb meat, as it is the most frequently purchased package size in the town where the experiment was conducted. They also suggested that, apart from the price, 2 attributes should be considered, the type of cut and the regional quality certification (protected geographical indication [PGI]). The type of packaging was designed with 2 levels-the regular tray and the vacuum packaging. The type of labels has 3 levels corresponding with 3 different stickers to provide the mandatory information, a conventional label -a small paper sticker with the mandatory information, an enhanced parent plastic sticker that allows the consumer to see the meat inside. For the price, 3 price levels for a half-kilo package of fresh lamb meat were defined to be representative of the lamb-meat price in the respondent's profile. This approach avoids systematic correlations of the experienced alternative. ${ }^{21}$ To take into account this extra varipaper sticker covering a higher proportion of the package, and a trans-
TABLE 1 Attributes and levels used in the choice design

\begin{tabular}{ll}
\hline Attributes & Levels \\
\hline Price (€/half kilo) & $\begin{array}{l}\text { 6, 7.5, and 9 (PRICE) } \\
\text { Leg steak (LEG) } \\
\text { Chops (CHOP) } \\
\text { Shank }\end{array}$ \\
\hline Type of cut & $\begin{array}{l}\text { PGI indication (PGI) } \\
\text { No PGI indication }\end{array}$ \\
\hline Regional quality certification & $\begin{array}{l}\text { Vacuum (VACUUM) } \\
\text { Conventional }\end{array}$ \\
\hline Type of packaging & $\begin{array}{l}\text { Enhanced paper sticker (LENHANCED) } \\
\text { Plastic transparent sticker (LPLASTIC) } \\
\text { Conventional paper sticker }\end{array}$ \\
\hline Type of label &
\end{tabular}

Levels in bold are reference levels in the model estimation.

among interactions inherent in fixed designs, and thus, both the main effects and the higher order interactions can be robustly estimated with sufficiently large sample sizes. For a choice set for 2 design alternatives plus a nonbuy option, we obtained 24 choice sets for main effects and 2-way interactions. ${ }^{24}$ The efficiency of the design was $95 \%$. To avoid fatigue effects associated with multiple scenario valuation tasks, the 24 sets were randomly split into 2 blocks of 12 choices. Thus, each respondent was asked to make 12 choices.

\subsection{Data collection}

Data were collected via a survey conducted in the medium-sized town (Zaragoza) located in the region (Aragón) with the highest production and consumption of lamb meat during May 2013. Moreover, this town was also selected because it is widely used by food marketers and market research consulting companies, as the sociodemographics are representative of the Spanish census of population (Table A1). Target TA1, respondents were adults who consume lamb meat and were food shoppers. The questionnaire was administrated in various supermarkets in different suburbs to people who were shopping at the moment. To do that, we contacted with a supermarket chain and asked the managers for permission to administer the survey in various shops in the supermarket chain throughout the town. This allows for interviewing food shoppers as well as fresh lamb-meat buyers because the interviewer was next to the fresh-meat refrigerators where other fresh meat products were placed. Then, the different fresh lamb-meat packages in the CE were also displayed in the refrigerators with the rest of fresh meat, which allows respondents to see the different packages and increase the environmental validity of the CE. The questionnaire was administered face-to-face by a single interviewer who also attended the previous discussions with the lamb-meat experts and was extensively briefed by the research team. Weekly follow-up meetings were arranged to identify any problems with the survey; however, no major problems were detected, and the process was maintained throughout the whole interview period. A stratified random sample of consumers was made on the basis of gender and age. The final sample size was 170 , resulting in a sampling error of $\pm 8 \%$, for a confidence level of $95.5 \%$ when estimating the proportion of individuals choosing one of the hypothetical options ( $p=q=0.5 ; k=2)$. The interviewer randomly selected and approached individuals who were close to the fresh-meat refrigerator, asking them 1 screening question about 
whether or not they consume lamb meat. In the case of a negative response, interviewers randomly selected another customer belonging to a given age group until they obtained a positive response to the question.

Summary statistics for the characteristics of the sample are pre-

2 sented in Table 2. About half of the respondents were female (55\%), very similar to the population percentage. Approximately one quarter of the respondents was between 35 and 44 years old or 45 to 54 years old. As shown in Table 2, our sample differs from the general population for age because it included fewer people older than 65 years old and younger than 34 . Only $15 \%$ of participants had a primary level of education or less. Then, a lower proportion of younger and older people was expected because in general, fewer food shoppers belong in

TABLE 2 Sample characterisation (\% unless stated otherwise)

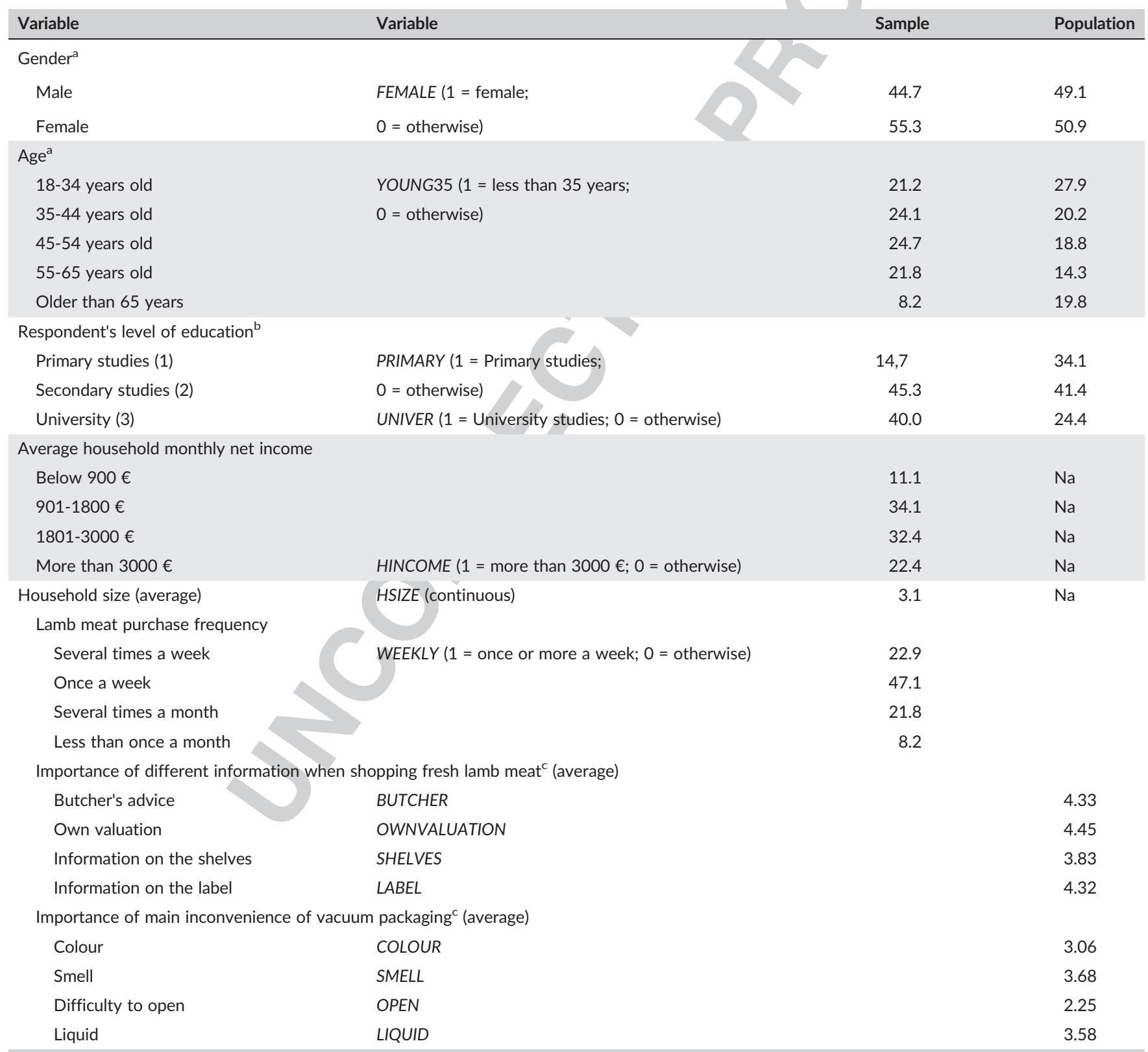

Abbreviation: $\mathrm{Na}$, not available.

aSpanish Census of Population, 2011. www.ine.es.

${ }^{\mathrm{b}} \mathrm{OECD} .^{25}$

${ }^{\mathrm{C} I m p o r t a n c e}$ scale from 1 (low importance) to 5 (high importance). those age groups. The higher proportion of people with university studies in the sample is common in all studies because more educated people are more prone to respond to questionnaires. Although underor over-representation of the sample is a feature common to many other surveys and empirical studies, ${ }^{26}$ it must be taken into account in the interpretation of results.

\section{4 | Model specification}

The final specification of the utility function included the different attribute levels and the alternative-specific constant (ASC) associated with the designed alternatives. The utility function is specified in the following way: 


$$
\begin{aligned}
& U_{n j t}=A S C+\beta_{1} P R I C E_{n j t}+\beta_{2} C H O P_{n j t}+\beta_{3} L E G_{n j t}+\beta_{4} P G I_{n j t} \\
& +\beta_{5} \text { VACUUM }_{n j t}+\beta_{6} \text { ENHANCED }_{n j t}+\beta_{7} \text { PLASTIC }_{n j t}+\varepsilon_{n j t},
\end{aligned}
$$

where $J$ indicates the 3 alternatives in the choice set and ASC is a dummy variable describing the designed alternatives. This means that value 1 corresponds with the designed alternatives and 0 represents the nonbuy option. The price variable represents the 3 price levels (6, 7.5, and 9) for the fresh lamb meat. For the different cuts, 2 dummy variables were built (CHOP and LEG) where 1 indicates the corresponding type of cut and 0 is otherwise (Table 1 ). The regional quality certification $(P G I)$ is a dummy variable where 1 indicates that the lamb meat carried the PGI indication and 0 indicates that it does not. The vacuum packaging variable (VACUUM) is also a dummy variable where 1 denotes the lamb meat packaged using the vacuum system and 0 represents the conventional packaging option. Finally, for the different type of labels, 2 dummy variables were defined. In particular, ENHANCED takes value 1 if the label is the extended paper sticker and 0 otherwise, and PLASTIC takes the value 1 if the label is the plastic transparent sticker and 0 otherwise. It was expected that the ASC would be positive and significant, indicating that consumers will gain higher utility from the designed alternatives ( $A$ and $B$ ) than from the nonbuy alternative. All coefficients, except for the price, were assumed to be random, following a normal distribution. Price was expected to have a negative impact on utility based on the economic theory, and the rest of the variables were expected to have a positive effect.

\section{3 | RESULTS AND DISCUSSION}

\subsection{Estimated utility parameters and relative importance of the attributes}

Depending on the assumptions on preferences and on the correlation between utilities and taste parameters, 3 different specifications of the utility equation were estimated. All estimations were conducted using NLOGIT 5.0. First, we assumed that consumers had homogenous preferences and an MNL model was specified. The second model relaxed this assumption of homogenous preferences, allowing preferences to be heterogeneous across individuals. Then, an RPL model, using the panel structure of the data and taking into account that each individual made 12 choices, ${ }^{20}$ was specified. Third, the existence of a correlation across utilities and tastes was considered, and an ECRPL model with correlated errors was specified. For the estimation of the RPL and ECRPL models, we used 200 Halton draws rather than pseudorandom draws since the former provides more accurate simulations. ${ }^{20}$

The estimation results for the 3 models are shown in Table 3. The first column presents the results for the multinomial model (MNL), the second column for the RPL, and the third presents the estimations for the ECRPL with correlated errors.

First, the standard deviations of the estimates were all statistically different from zero at the $1 \%$ significance level, indicating that consumer heterogeneity exists. Thus, the RPL model was a better specification than the MNL. Moreover, the log-likelihood value at convergence and the pseudo $R^{2}$ reach their best value in the RPL model compared to the MNL model, corroborating the idea that the former was a better specification than the latter. Comparing the RPL and the ECRPL, the log-likelihood value at convergence and the pseudo $R^{2}$ slightly decrease and increase, respectively, indicating that the ECRPL model was better than the RPL. Moreover, the $\sigma_{\varepsilon}$ for the error component was statistically significant, consistent with the idea that an error component model must be specified. In addition, 2 of the values in the diagonal of the Cholesky matrix were statistically significant at the 5\% level, indicating that the errors were correlated and, thus, a multivariate normal distribution was the best assumption. Therefore, the ECRPL model was selected for further analysis.

As expected, the ASC was positive and significant, indicating that consumers obtain higher utility from choosing any alternative than from the nonbuy option. Moreover, the price variable (PRICE) was negative and statistically significant in accordance with the economic theory. All of the coefficients for the attribute levels were statistically significant except for the type of label, of which both estimated parameters were statistically equal to zero (ENHANCED and PLASTIC), indicating that consumers value the 3 types of label the same. The rest of the statistically significant estimated coefficients were positive.

The positive estimated coefficient for the vacuum packaging (VACUUM) indicated that consumers gain higher utility for this packaging than for the conventional. Then, we found that vacuum packaging for fresh lamb meat is accepted by lamb-meat consumers. The 2 types of cut coefficients (LEG and CHOPS) were positive, which means that consumers get higher utility for a package of fresh leg steak and chops than they do for a package of shanks. This result was expected because these 2 cuts are indeed the most popular for consumers in the town, and therefore, they used to be more expensive in the meat stores. The PGI indication variable was also positive, indicating that consumers attained higher utility for a package of lamb meat with the PGI indication than for the meat without this regional certification. This result is consistent with the existing literature on valuation of PDO and PGI indications for food products, and for meat in particular. In the case of meats with PGI, the quality label is frequency linked to a production region, and the origin of lamb meat is one of the aspects that is most highly valued by consumers. ${ }^{27-31}$

Although we found evidence that vacuum packaging for fresh lamb meat is accepted, we are interested on the importance consumers attached to this packaging in relation to the other attributes. Then, based on parameters estimates, the relative importance for each of the attribute levels was assessed. The importance scores (IS) were calculated by multiplying the absolute value of the estimated coefficients by the difference between the highest and the lowest of each attribute level. ${ }^{32}$ The score measures the extent to which consumers' utility changes as the level of the attribute is altered and is calculated as follows:

$$
I S_{1}=\frac{\beta_{1}(\text { Highest }- \text { Lowest })}{\sum_{1}^{7} \beta_{k}(\text { Highest }- \text { Lowest })},
$$

where $k$ indicates the number of attribute levels, in our case, 1 to 7 (Equation 2).

Table 4 presents the relative importance of the lamb-meat attribute levels and shows that the most important attribute levels were 
TABLE 3 Estimates for the parameter models

\begin{tabular}{|c|c|c|c|}
\hline & MNL & RPL & ECRPL \\
\hline \multicolumn{4}{|l|}{ Mean values } \\
\hline ASC & $1.6266(7.05)^{* * *}$ & $1.9717(6.82)^{* * *}$ & $2.92(8.03)^{* * *}$ \\
\hline LEG & $0.2952(3.73)^{* * *}$ & $0.5095(4.24)^{* * *}$ & $0.4807(4.38)^{* * *}$ \\
\hline $\mathrm{CHOP}$ & $0.7957(9.26)^{* * *}$ & $1.2396(8.86)^{* * *}$ & $1.3151(6.98)^{* * *}$ \\
\hline LENHANCED & $0.0679(0.92)$ & $0.1386(1.29)$ & $0.0180(0.11)$ \\
\hline LPLASTIC & $0.0921(1.19)$ & $0.2013(1.64)$ & $0.1298(0.80)$ \\
\hline \multicolumn{4}{|c|}{ Standard deviations of parameter distributions } \\
\hline LEG & - & $0.7612(5.45)^{* * *}$ & $0.7392(5.40)^{* * *}$ \\
\hline $\mathrm{CHOP}$ & - & $0.9777(5.89)^{* * *}$ & $1.3579(6.70)^{* * *}$ \\
\hline LPLASTIC & - & $0.8204(5.99)^{* * *}$ & $1.1113(5.25)^{* * *}$ \\
\hline \multicolumn{4}{|c|}{ Diagonal values in Cholesky matrix } \\
\hline LEG & - & - & $0.7392(5.40)^{* * *}$ \\
\hline $\mathrm{CHOP}$ & - & - & $0.0086(0.04)$ \\
\hline PGI & - & - & $0.0228(0.09)$ \\
\hline VACUUM & - & - & $0.0581(0.21)$ \\
\hline LENHANCED & - & - & $0.4333(1.74)^{*}$ \\
\hline LPLASTIC & - & - & $0.6833(2.58)^{* * *}$ \\
\hline \multicolumn{4}{|c|}{ Standard deviation of the latent random effect } \\
\hline
\end{tabular}

Abbreviations: ASC, alternative-specific constant; ECRPL, error-component random-parameters logit; MNL, multinomial logit; PGI, protected geographical indication; RPL, random parameters logit.

Wald statistics are in parenthesis

*Significance at $10 \%$.

${ }^{* *}$ Significance at $5 \%$.

${ }^{* * *}$ Significance at $1 \%$.

the PGI certification followed by the chops, the price, and the leg steak. The less important attribute levels were the vacuum packaging, the plastic sticker, and the enhanced sticker. Then, we can concluded that consumers would accept the vacuum packaging for fresh lamb meat but their valuation is lower than the valuation of other attributes such as quality certification (PGI). On the other hand, the new labels did not receive higher valuation than the regular used label.

TABLE 4 Relative importance of the lamb-meat attribute levels (\%)

\begin{tabular}{lr}
\hline PRICE & 13.9 \\
LEG & 10.3 \\
CHOP & 28.3 \\
PGI & 37.8 \\
VACUUM & 6.5 \\
LENHANCED & 0.4 \\
LPLASTIC & 2.8 \\
\hline
\end{tabular}

\subsection{Interaction analysis between the vacuum packaging and the rest of the attributes}

To further investigate acceptance of the vacuum packaging, we analysed the interaction between the vacuum packaging and the rest of attribute levels to see if this type of packaging was more accepted for some types of attributes. To conduct this analysis, we included in the previous ECRPL model** ${ }^{* *}$ the way interactions between the vacuum packaging and the rest of the attribute levels. The new utility function to be estimated is as follows:

$$
\begin{aligned}
U_{n j t}= & A S C+\beta_{1} P_{R I C E_{n j t}}+\beta_{2} \text { CHOP }_{n j t}+\beta_{3} L_{E G_{n j t}}+\beta_{4} P \text { II I }_{n j t} \\
& +\beta_{5} \text { VACUUM }_{n j t}+\beta_{6} \text { CHOP }^{*} \text { VACUUM }_{n j t}+\beta_{7} \text { LEG }^{*} \text { VACUUM }_{n j t} \\
& +\beta_{8} \text { PGI }^{*} \text { VACUUM }_{n j t}+\varepsilon_{n j t},
\end{aligned}
$$

where the interactions among the vacuum packaging dummy variable and the rest of attribute level dummies were calculated by multiplying them (CHOP*VACUUM, LEG*VACUUM, and PGI*VACUUM). 
Table 5 shows the estimate coefficients for the ECRPL model with interaction dummies. First, we observed that the only interaction term estimated parameter statistically different from zero at the $5 \%$ significance level was the PGI*VACUUM. The positive value for the interaction between the $\mathrm{PGI}$ indication and the vacuum packaging (PGI*VACUUM) indicated that consumer's utility for the lamb meat with both the regional PGI indication and the vacuum packaging is higher than is the sum of the utilities derived by either the PGI indication or the vacuum packaging. Thus, combining the regional PGI indication and the vacuum packaging in lamb meat is a better strategy because consumers attached more value in this combination than they do for the provision of each of the characteristics (PGI and vacuum packaging, respectively). Moreover, it was observed that the main effect of the vacuum packaging on the utility was now no longer statistically different from zero. These 2 results indicated that the vacuum packaging

TABLE 5 Estimates for the parameter model with interaction effects

\begin{tabular}{|c|c|c|}
\hline & ECRPL & ECRPL-Final \\
\hline ASC & $3.5077(8.73)^{* * *}$ & $3.3342(9.05)^{* * *}$ \\
\hline PRICE & $-0.2031(-6.14)^{* * *}$ & $-0.1919(-7.01)^{* * *}$ \\
\hline LEG & $0.4112(1.65)^{*}$ & $0.4521(3.60)^{* * *}$ \\
\hline $\mathrm{CHOP}$ & $1.3205(4.93)^{* * *}$ & $1.0847(6.95)^{* * *}$ \\
\hline$P G I$ & $1.1024(3.33)^{* * *}$ & $1.0562(6.67)^{* * *}$ \\
\hline VACUUM & $-0.3187(-0.82)$ & - \\
\hline LEG*VACUUM & $0.3324(0.62)$ & - \\
\hline CHOP*VACUUM & $-0.1727(-0.4)$ & - \\
\hline PGI*VACUUM & $0.9798(1.96)^{* *}$ & $0.5307(2.95)^{* * *}$ \\
\hline \multicolumn{3}{|c|}{ Standard deviations of parameter distributions } \\
\hline LEG & $0.5287(1.83)^{*}$ & $0.9015(6.88)^{* * *}$ \\
\hline $\mathrm{CHOP}$ & $1.3932(3.78)^{* * *}$ & $1.0724(5.61)^{* * *}$ \\
\hline PGI & $2.0523(6.49)^{* * *}$ & $1.7472(9.92)^{* * *}$ \\
\hline VACUUM & $0.7625(2.01)^{* * *}$ & - \\
\hline LEG*VACUUM & $1.5837(3.05)^{* * *}$ & $->$ \\
\hline CHOP*VACUUM & $1.3968(3.08)^{* * *}$ & - \\
\hline PGI*VACUUM & $1.5760(2.75)^{* * *}$ & $1.6845(11.05)^{* * *}$ \\
\hline \multicolumn{3}{|c|}{ Diagonal values in Cholesky matrix } \\
\hline LEG & $0.5287(1.83)^{*}$ & $0.9015(6.88)^{* * *}$ \\
\hline $\mathrm{CHOP}$ & $0.1095(0.28)$ & $0.8256(5.72)^{* * *}$ \\
\hline$P G I$ & $0.6811(1.17)$ & $1.5855(8.48)^{* * *}$ \\
\hline VACUUM & $0.0831(0.11)^{* * *}$ & - \\
\hline LEG*VACUUM & $1.0901(3.65)^{* * *}$ & - \\
\hline CHOP*VACUUM & $0.2058(0.31)$ & - \\
\hline PGI*VACUUM & $0.6844(1.57)$ & $1.2426(9.42)^{* * *}$ \\
\hline$\sigma_{\varepsilon}$ & $2.2562(6.46)^{* * *}$ & $2.2644(9.46)^{* * *}$ \\
\hline $\mathrm{N}$ & 2040 & 2040 \\
\hline Log-likelihood & -1402.83 & -1421.79 \\
\hline Pseudo $R^{2}$ & 0.37 & 0.37 \\
\hline
\end{tabular}

Abbreviations: ASC, alternative-specific constant; ECRPL, error-component random-parameters logit; MNL, multinomial logit; PGI, protected geographical indication; RPL, random parameters logit.

${ }^{*}$ Significance at $10 \%$.

${ }^{* *}$ Significance at $5 \%$.

${ }^{* * *}$ Significance at $1 \%$. was only valued by consumers in the case of the fresh lamb meat with the PGI indication. This result is new in the literature because as far as we know, no other previous research already analysed this issue. This finding indicated that consumers attain higher utility for the vacuum packaging only for the meat of higher quality, in this case, for the lamb meat having the PGI certification. This finding is important for lambmeat producers because they can take advantage of this higher joint valuation and introduce vacuum packaging in the market for this higher quality meat (lamb meat with PGI). Once the vacuum packaging is accepted for this type of certified lamb meat and becomes better known to the consumers, the lamb sector could start using it for other cuts of lamb meat.

Finally, the other 2 interaction terms in the model were not statistically significant, which means that the vacuum packaging did not add any value to the type of cut (LEG or CHOP). We can conclude that the regional $\mathrm{PGI}$ indication and the vacuum packaging are complementary attributes and both should be used together to differentiate the fresh lamb meat in the market and reach consumers who value these 2 attributes the most.

We also observe in Table 5 that consumers' preferences were heterogeneous for the different attribute levels and for the interaction between the PGI and vacuum packaging because the standard deviations were statistically significant. This indicates that consumers' utilities differ across consumers for the different attributes and for their combination. To better understand the reasons for this heterogeneity, we investigated the main determinants of consumers' valuation for the vacuum packaging. To do this, we take the utilities of the interaction between the PGI and the vacuum packaging ( $\beta_{8}$ in Equation 4) for each of the respondents from the final estimated model in Table 5 (last column). Then, these estimated utilities were regressed on different consumer characteristics: purchase behaviour, opinions on vacuum packaging, and sociodemographic and economic variables. In particular, the explanatory variables in this regression are defined in Table 2.

This model was estimated using ordinary least square because the dependent variable has a continuous nature. Table 6 shows the estimated parameters for the consumers' utilities for both the PGI and the vacuum packaging attributes. First, only the explanatory variables that were statistically significant different from zero were maintained in the final estimated model. This model was overall statistically significant ( $F$ values reject the null hypothesis that all estimated parameters are equal to zero at the $5 \%$ significance level), and the explanatory variables that were ultimately included explained a reasonable part of the utility heterogeneity (adjusted $R^{2}$ value was 0.13 ). Robust $t$ ratios were reported for individual parameter significance to correct for heteroscedasticity. ${ }^{33}$

The results indicated that few explanatory factors were statistically significant. Only 1 sociodemographic consumer characteristic explained the utility for both attributes (PGI and VACUUM). The negative value for the estimated coefficient for the variable YOUNG35 indicated that consumers younger than 35 years old placed a lower value on fresh lamb meat with PGI using a vacuum package. Although this result is new because no other paper analyses this particular issue, we found a similar result in Chen et al, ${ }^{15}$ which stated that WTP for vacuum-packaged beef steaks increased with other socio-economic 
TABLE 6 Factors affecting individual utilities for the lamb meat with PGI and vacuum package

\begin{tabular}{lll} 
& Estimates & $t$ Ratios \\
\hline Constant & -0.8497 & -1.3 \\
$\begin{array}{l}\text { Sociodemographics } \\
\text { YOUNG35 }\end{array}$ & -0.5127 & $-2.36^{* *}$ \\
Importance of information & & \\
$\quad$ OWNVALUATION & 0.2774 & $2.87^{* *}$ \\
LABEL & 0.2043 & $1.67^{*}$ \\
Importance of vacuum inconvenience & \\
$\quad$ LIQUID & -0.2120 & $-3.32^{* *}$ \\
F value & 6.04 & \\
Adjusted $\mathrm{R}^{2}$ & 0.13 & \\
\hline
\end{tabular}

Abbreviation: PGI, protected geographical indication.

Number of observations $=170 /$ Robust White $(1980) t$ ratios are reported.

*Statistically significant at $10 \%$.

${ }^{* *}$ Statistically significant at $5 \%$.

characteristics such as the level of education, level of income, and the presence of children in the household. In addition, Angulo et $\mathrm{al}^{34}$ and Sepúlveda et $\mathrm{al}^{35}$ found a relationship between the consumer's age and quality-labelled lamb meat.

The estimated coefficients for the variables OWNVALUATION and $\angle A B E L$ were positive and statistically significant. This result indicates that consumers who, when shopping for fresh lamb meat, used their own evaluation of the product and the information in the label placed a higher value on the lamb meat with PGI using a vacuum package. In other words, the direct appraisal by consumers when shopping is 1 important aspect that increases consumers' valuation of the lamb meat with the vacuum packaging. This result is in agreement with Sepúlveda et al, ${ }^{36}$ which stated that direct appraisal was the aspect most valued by all groups of buyers to infer the quality of meat at the time of purchase. Consumers that attach higher importance when shopping to their direct appraisal and the information on the label are likely to be more prone to buy fresh meat at the supermarket where they cannot be advised by the butcher. Thus, we can assume that this segment of consumers could place a higher value on the lamb meat already prepared with vacuum packaging having a quality level already certified by the PGI.

Finally, the negative and statistically significant estimated coefficient for the variable LIQUID indicated that consumers who highly believe that the main inconvenient of the vacuum packing is the formation of liquid around the meat showed lower value for the lamb meat with PGI using a vacuum package. This result was indeed expected and should be taken into account when making recommendations to producers.

Then, we can conclude that the vacuum packaging is valued for consumers but only for the fresh lamb meat with PGI indication and that consumers' valuation of this meat depends on the consumers' age, own evaluation when shopping, information on food labels, and perceived inconvenience of vacuum packaging (liquid around the meat).

\section{4 | CONCLUSIONS}

The significant decrease in the consumption of lamb meat has resulted in different problems along the supply chain. In particular, there are problems with lamb meat on supermarket shelves because fresh lamb meat is a highly perishable product with low turnover rate. The use of vacuum packaging could contribute to extending the shelf life of the product and mitigating these problems. However, although vacuum packaging has been used for other meat products (eg, cured meat), it has been never utilized to sell fresh lamb meat in Spanish supermarkets. Then, it is difficult to anticipate whether lamb-meat consumers would accept the vacuum packaging for this particular fresh meat. Our results confirmed that consumers positively value the vacuum packaging but to lesser extent that other lamb meat attributes such as the type of cut, the PGI certification, and the price. Moreover, we found that consumers only value the vacuum packaging in the case of fresh lamb meat with the PGI certification. This result is of relevant interest because it indicates that the introduction of the vacuum packaging would be accepted by consumers but mainly for the higher quality meats with a PGI certification.

Because of the increase amount of mandatory information to display in the package for meat products, the role of communication of the package becomes more important. Then, new labels were designed to enhance the communication function. However, results indicated that the new labels (enhanced and plastic) were not more valued by consumers than the conventional used labels.

Although these results are very promising, we have to point out that this work, however, does have 1 main shortcoming due to cost and time constraints-the sample size of this study was relatively small, and the survey was only conducted in 1 particular town in Spain. This fact must be taken into account when interpreting the results. To generalise the conclusions, additional similar studies should be performed for larger samples and in other geographical areas.

\section{ENDNOTES}

† Vacuum preserves the meat from oxidative deterioration because the elimination of the oxygen impedes the ability of oxygen-breathing microorganisms to grow and spoil the product. Another advantage of the vacuum packaging is that water loss from the meat is avoided. ${ }^{8,9}$ However, in the case of fresh meat, removing oxygen can distort the appearance of the product; in particular, the meat turns a purple-brown colour that is distinctly different from the bright red colour of the conventional tray-packaged fresh meat. However, the initial colour of the meat (redness) can be partially recovered when the pack is opened and the meat is exposed to air. ${ }^{10-12}$

₹ Per capita lamb consumption in the region in 2013 accounted for $4.93 \mathrm{~kg} /$ person/year versus $1.93 \mathrm{~kg} /$ person/year in the rest of Spain and was the region with the highest per capita consumption. ${ }^{17}$

$\S$ Consumers in the experiment faced real products as examples, but we did not conduct a real choice experiment because only few packages of lamb meat with vacuum packaging were prepared for a company to be used in the experiment.

** We dropped the 2 label variables (ENHANCED and PLASTIC) because they were not statistically significant in the previous estimations.

ORCID

Azucena Gracia http://orcid.org/0000-0003-3096-302X 


\section{REFERENCES}

1. Duizer LM, Robertson T, Han J. Requirements for packaging from an ageing consumer's perspective. Packag Technol Sci. 2009;22(4): 187-197.

2. Joutsela M, Latvala T, Roto V. Influence of packaging interaction experience on willingness to pay. Packag Technol Sci. 2016;

3. Font-i-Furnols M, Guerrero L. Consumer preference, behavior and perception about meat and meat products: an overview. Meat Sci. 2014;98(3):361-371.

4. Agriculture and Horticulture Development Board (AHDB) and International Meat Secretariat, 2015. World sheep meat market to 2025. Available at http://www.meat-ims.org/wp-content/uploads/2016/01/ World-sheep-meat-market-to-2025.pdf (accessed, 1 February 2017).

5. Martín V. Consumo de carne de ovino en España. Distribución y consumo. 2012;122:89-93.

6. MERCASA, 2016. La alimentación en España en 2016. Available at http://www.mercasa-ediciones.es/alimentacion_2016/3_info_sectores2.html (accessed, 1 February 2017).

7. Blasco M., Sañudo C., Balado J., Campo M.M. Actitudes de compra y consumo de carne de cordero. Estudio comparativo de consumidores en Zaragoza y Castellón. AIDA (2017), XVII Jornadas sobre Producción Animal, 729-731. Available at http://www.aida-itea.org/aida-itea/ files/jornadas/2017/comunicaciones/2017_CdP_53.pdf. (accessed, 21 August 2017).

8. Li X, Lindahl G, Zamaratskaia G, Lundström K. Influence of vacuum skin packaging on color stability of beef longissimus lumborum compared with vacuum and high-oxygen modified atmosphere packaging. Meat Sci. 2012;92(4):604-609.

9. Summo C, Caponio F, Pasqualone A. Effect of vacuum-packaging storage on the quality level of ripened sausages. Meat Sci. 2006;74(2): 249-254.

10. Cachaldora A, García G, Lorenzo JM, García-Fontán MC. Effect of modified atmosphere and vacuum packaging on some quality characteristics and the shelf life of "morcilla", a typical cooked blood sausage. Meat Sci. 2013;93(2):220-225.

11. García-Esteban M, Ansorena D, Astiasarán I. Comparison of modified atmosphere packaging and vacuum packaging for long period storage of dry-cured ham: effects on colour, texture and microbiological quality. Meat Sci. 2004;67(1):57-63.

12. Lorenzo JM, Gómez M. Shelf life of fresh foal meat under MAP, overwrap and vacuum packaging conditions. Meat Sci. 2012;92(4): 610-618.

13. Zhou GH, Xu XL, Liu Y. Preservation technologies for fresh meat - a review. Meat Sci. 2010;86(1):119-128.

14. Schmitz D, Menkhaus J, Whipple D, Hoffman E, Field A. Impact of changing consumer preferences on willingness-to-pay for beef steaks in alternative retail packaging. J Food Distribution Res. 1993;24(2):2335.

15. Chen Q, Anders S, An H. Measuring consumer resistance to a new food technology: a choice experiment in meat packaging. Food Qual Prefer. 2013;28(2):419-428.

16. Grebitus C, Jensen HH, Roosen J. US and German consumer preferences for ground beef packaged under a modified atmosphere different regulations, different behaviour? Food Policy. 2013;40: 109-118.

17. MAGRAMA. Ministerio de Agricultura, Alimentación y Medio Ambiente. Gobierno de España: Datos de consumo alimentario en España; 2013:2013. Available at: http://www.magrama.gob.es/ es/alimentacion/temas/consumo-y-comercializacion-y-distribucion- alimentaria/panel-de-consumo-alimentario/base-de-datos-de-consumoen-hogares/resultado1.asp accessed, 1 February 2017.

18. Adamowicz W, Boxall P, Williams M, Louviere J. Stated preference approaches for measuring passive use values: choice experiments and contingent valuation. Am J Agric Econ. 1998;80(1):64-75.

19. McFadden D. Conditional logit analysis of qualitative choice behavior. In: Zarembka P, ed. Frontiers in Econometrics. Academic Press: New York; 1974:105-142.

20. Train K. Discrete Choice Methods with Simulation. Cambridge: Cambridge University Press; 2003.

21. Scarpa R, Campbell D, Hutchinson G. Benefit estimates for landscape improvements: sequential Bayesian design and respondents rationality in a choice experiment. Land Econ. 2007;83(4):617-634.

22. Campbell D. Willingness to pay for rural landscape improvements: combining mixed logit and random effects models. J Agric Econ. 2007;58(3):467-483.

23. Scarpa R, Del Giudice T. Market segmentation via mixed logit: extravirgin olive oil in urban Italy. J Agric Food Ind Organ. 2004;2(7):

24. Sawtooth Software Market Research Tools, Inc, 2013. CBC system.

25. OECD, 2013. Education at a Glance 2013: OECD Indicators. Available at: http://www.oecd.org/edu/eag2013\%20\%28eng\%29--FINAL\% 2020\%20June\%202013.Pdf. (accessed, 1 February 2017).

26. Verhoef PC. Explaining purchase of organic meat by Dutch consumers. Eur Rev Agric Econ. 2005;32(2):245-267.

27. Bernabéu R, Tendero A. Preference structure for lamb meat consumers. A Spanish case study. Meat Sci. 2005;71:464-470.

28. Bernués A, Olaizola A, Corcoran K. Labelling information demanded by European consumers and relationships with purchasing motives, quality and safety of meat. Meat Sci. 2003;65:1095-1106.

29. Gracia A. Comportamiento del consumidor en la compra de carne de cordero con IGP-Ternasco de Aragón. Revista Española de Estudios Agro-Sociales y Pesqueros. 2005;206:137-161.

30. Sánchez M, Sanjuán Al, Akl G. El distintivo de calidad como indicador de seguridad alimenticia en carne de vacuno y cordero. Economía Agraria y Recursos Naturales. 2001;1(1):77-94.

31. Ulloa RR, Gil JM. Importancia de la marca ternasco de Aragón con IGP medida a través del método de análisis conjunto desde el punto de vista del consumidor. Revista Mexicana de Agronegocios. 2007;21:408-423.

32. Chang JB, Moon W, Balasubramanian AK. Consumer valuation of health attributes for soy-based food: a choice modeling approach. Food Policy. 2012;37(3):335-342.

33. Greene WH. Econometric Analysis. 6th ed. New Jersey: Prentice Hall; 2008.

34. Angulo AM, Gil JM, Tamburo L. Food safety and consumers' willingness to pay for labelled beef in Spain. J Food Prod Mark. 2005;11(3):89-105.

35. Sepúlveda W, Maza MT, Mantecón AR. Factors that affect and motivate the purchase of quality labelled beef in Spain. Meat Sci. 2008;80(4):1282-1289.

36. Sepúlveda W, Maza MT, Mantecón AR. Factors associated with the purchase of designation of origin lamb meat. Meat Sci. 2010;85: 167-173.

How to cite this article: Maza MT, Gracia A, Saied M. Consumers' valuation of two packaging aspects for fresh lamb meat: Vacuum and information labels. Packag Technol Sci. 2017;1-10. https://doi.org/10.1002/pts.2357 
$10 \quad$ WI LEY-Packaging Technology and Science

\section{APPENDIX}

ANNEX. POPULATION IN SPAIN AND THE TOWN

TABLE A1 Population by sex and age in Spain and in the town (\%)

\begin{tabular}{|c|c|c|c|c|c|c|c|c|}
\hline & \multicolumn{3}{|c|}{ Sex } & \multicolumn{5}{|l|}{ Age } \\
\hline & Total & Female & Male & $0-19$ & $20-34$ & $35-54$ & $55-64$ & More than 64 \\
\hline Spain & 46148605 & 50.99 & 49.01 & 19.88 & 20.80 & 31.10 & 11.05 & 17.14 \\
\hline
\end{tabular}

Source: Spanish Census of Population, 2011. www.ine.es. 